\title{
Cryo-Immunogold Electron Microscopy for Prions: Toward Identification of a Conversion Site
}

\author{
Susan F. Godsave, ${ }^{1}$ Holger Wille, ${ }^{2,3}$ Pekka Kujala, ${ }^{1}$ Diane Latawiec, ${ }^{2,3}$ Stephen J. DeArmond, ${ }^{2,3,4}$ Ana Serban, ${ }^{2}$ \\ Stanley B. Prusiner, ${ }^{2,3}$ and Peter J. Peters ${ }^{1}$ \\ ${ }^{1}$ Section of Tumor Biology, Netherlands Cancer Institute, 1066 CX Amsterdam, The Netherlands, ${ }^{2}$ Institute for Neurodegenerative Diseases, and \\ Departments of ${ }^{3}$ Neurology and ${ }^{4}$ Pathology, University of California, San Francisco, San Francisco, California 94143
}

\begin{abstract}
Prion diseases are caused by accumulation of an abnormally folded isoform $\left(\operatorname{PrP}^{\mathrm{sc}}\right)$ of the cellular prion protein $\left(\operatorname{PrP}^{\mathrm{C}}\right)$. The subcellular distribution of $\operatorname{PrP}^{\mathrm{Sc}}$ and the site of its formation in brain are still unclear. We performed quantitative cryo-immunogold electron microscopy on hippocampal sections from mice infected with the Rocky Mountain Laboratory strain of prions. Two antibodies were used: $\mathrm{R} 2$, which recognizes both $\operatorname{PrP}^{\mathrm{C}}$ and $\operatorname{PrP}^{\mathrm{Sc}}$; and F4-31, which only detects $\operatorname{PrP}^{\mathrm{C}}$ in undenatured sections. At a late subclinical stage of prion infection, both $\operatorname{PrP}^{\mathrm{C}}$ and $\mathrm{PrP}^{\mathrm{Sc}}$ were detected principally on neuronal plasma membranes and on vesicles resembling early endocytic or recycling vesicles in the neuropil. The R2 labeling was approximately six times higher in the infected than the uninfected hippocampus and gold clusters were only evident in infected tissue. The biggest increase in labeling density (24-fold) was found on the early/recycling endosome-like vesicles of small-diameter neurites, suggesting these as possible sites of conversion. Trypsin digestion of infected hippocampal sections resulted in a reduction in $\mathrm{R} 2$ labeling of $>85 \%$, which suggests that a high proportion of $\operatorname{PrP}^{\mathrm{Sc}}$ may be oligomeric, protease-sensitive $\operatorname{PrP}^{\mathrm{Sc}}$.
\end{abstract}

Key words: prion; electron microscopy; trypsin; endosome; cryo-immunogold EM; plasma membrane

\section{Introduction}

The prion diseases include Creutzfeldt-Jakob disease (CJD) in humans, bovine spongiform encephalopathy in cows, and scrapie in sheep and goats. These are incurable neurodegenerative diseases caused by accumulation of an abnormally folded form $\left(\mathrm{PrP}^{\mathrm{Sc}}\right)$ of the cellular prion protein $\left(\operatorname{PrP}^{\mathrm{C}}\right)$. As $\operatorname{PrP}^{\mathrm{Sc}}$ accumulates, spongiform degeneration and reactive astrocytic gliosis ensue (DeArmond, 2004). $\mathrm{PrP}^{\mathrm{C}}$ is a GPI-linked membrane protein that is widely expressed, but is present at higher levels in the CNS, where prion pathology is found. Elimination of the gene encoding $\operatorname{PrP}^{\mathrm{C}}$ renders mice resistant to prion diseases by removing the substrate for $\operatorname{PrP}^{\mathrm{Sc}}$ formation (Büeler et al., 1993).

The conversion of $\operatorname{PrP}^{\mathrm{C}}$ to $\operatorname{PrP}^{\mathrm{Sc}}$ is a post-translational event.

Received Sept. 16, 2008; accepted 0ct. 5, 2008.

This work was supported by European Union grants, AntePrion LSHB-CT-2006-019090, StrainBarrier F00D-CT2006-023183, and ImmunoPrion F00D-CT-2006-023144, as well as National Institutes of Health Grants (AG02132, AG10770, and AG021601). We also gratefully acknowledge a gift from the G. Harold and Leila Y. Mathers Charitable Foundation. We are grateful to the following: Prof. Terry Mayhew (University of Nottingham, Nottingham, UK) and Andrew Vincent [Netherlands Cancer Institute (NKI), Amsterdam, The Netherlands] for assistance with the statistical analyses, Yevgeniy Freyman and Quinn Walker [Institute for Neurodegenerative Diseases, University of California, San Francisco (UCSF), San Francisco, CA] for their help with the perfusions, Clarissa Bush (UCSF) for help with the Thioflavin-S staining, Dr. Jiri Safar (Institute for Neurodegenerative Diseases, UCSF), Dr. Carsten Korth (University of Duesseldorf, Duesseldorf, Germany), Dr. Alexander Mironov (University of Manchester, Manchester, UK), and Dr. Kees Jalink (NKI) for comments on this manuscript. We also thank Prof. Rytis Prekeris (University of Colorado Health Sciences (enter in Denver, Denver, (0) for the gift of anti-syntaxin 13 antibody and Prof. Anthony Williamson (Scripps Research Institute, La Jolla, (A) for R2 antibody fab fragments.

Correspondence should be addressed to Peter J. Peters, Netherlands Cancer Institute, Antoni van Leeuwenhoek Hospital, Plesmanlaan 121-H4, 1066 CX Amsterdam, The Netherlands. E-mail: p.peters@nki.nl.

D. Latawiec's present address: Prion Biology Laboratory, International School for Advanced Studies-Neurobiology Sector, 34014 Trieste, Italy.

D01:10.1523/JNEUROSCI.4474-08.2008

Copyright $\odot 2008$ Society for Neuroscience $\quad 0270-6474 / 08 / 2812489-11 \$ 15.00 / 0$
It is important to know how and where the conformational change occurs to develop effective strategies for treating these invariably fatal diseases. There is evidence that this occurs at the plasma membrane (PM) or in the endocytic pathway (for review, see Campana et al., 2005), but the details remain unknown. Several immuno-electron microscopy (EM) studies have targeted PrP in prion-infected brain, but no consensus has emerged over its subcellular distribution (Campana et al., 2005). Also, $\operatorname{PrP}^{C}$ and $\operatorname{PrP}^{S c}$ have the same primary structure, and methods for distinguishing them at the subcellular level on tissue sections have not yet been presented. Most, if not all, monoclonal antibodies that were purported to be specific for $\operatorname{PrP}^{\mathrm{Sc}}$ react poorly with aldehyde-fixed tissue, and in fact recognize insoluble, aggregated forms of PrP, including nonpathogenic PrP aggregates (Biasini et al., 2008), and possibly excluding the lowest molecular weight forms of $\operatorname{PrP}^{\mathrm{Sc}}$.

Following $\operatorname{PrP}^{\mathrm{C}}$ to $\operatorname{PrP}^{\mathrm{Sc}}$ conversion, $\operatorname{PrP}^{\mathrm{Sc}}$ can exist in various aggregation states with different sensitivities to proteolytic enzymes. The presence of proteinase $\mathrm{K}(\mathrm{PK})$-resistant $\mathrm{PrP}^{\mathrm{Sc}}$ has been used in diagnosing prion disease, but it is now clear that PK-sensitive, oligomeric forms can form a very high proportion of the total PrP ${ }^{\mathrm{Sc}}$ levels (Safar et al., 1998; Tzaban et al., 2002; Safar et al., 2005b; Pastrana et al., 2006; Thackray et al., 2007) and may be relevant for disease pathogenesis.

Here, we used quantitative cryo-immunogold EM to investigate the subcellular distribution of $\operatorname{PrP}$ in prion-infected tissue and to identify possible $\operatorname{PrP}^{\mathrm{C}}$-to- $\mathrm{PrP}^{\mathrm{Sc}}$ conversion sites. Previously, we used this technique on hippocampal sections of noninfected FVB mice and showed that $\operatorname{PrP}^{\mathrm{C}}$ is present predominantly on the plasma membrane of dendrites and axons as well as in 
parts of the biosynthetic and endocytic pathways (Mironov et al., 2003). We have now developed methods for comparing the distributions of $\operatorname{PrP}^{\mathrm{C}}$ and $\operatorname{PrP}^{\mathrm{Sc}}$ using two antibodies with different specificities and statistical analysis, and have applied these to prion-infected mouse hippocampus. Our results highlight vesicles resembling early/recycling endosomes as important sites of $\mathrm{PrP}^{\mathrm{Sc}}$ localization. PrP levels on plasma membranes also increased significantly after prion infection. Trypsin treatment of sections reduced specific $\mathrm{R} 2$ labeling by $>85 \%$ in both uninfected and prion-infected tissue, suggesting that a large proportion of $\mathrm{PrP}^{\mathrm{Sc}}$ in the hippocampus is protease-sensitive.

\section{Materials and Methods}

Animals and preparation of tissue. Wild-type FVB and PrP-ablated $\left(P_{n} p^{0 / 0}\right)$ mice were infected by intracerebral injection of $30 \mu \mathrm{l}$ of $1 \%$ brain homogenate from mice infected with Rocky Mountain Laboratory (RML) prions or from normal mice as controls. For immunolabeling studies, three RML-injected mice were killed at 104-106 d post inoculation (dpi). Two RML-inoculated $\operatorname{Prn} p^{0 / 0}$ mice and three FVB mice injected with normal brain homogenate were killed at 116 dpi. For Thioflavin-S staining, three RML-injected mice were killed at 113 dpi. In these mice, onset of overt prion disease occurs at $\sim 120 \mathrm{dpi}$. Mice were killed according to the Public Health Services/National Institutes of Health Guide for the Care and Use of Laboratory Animals and transcardially perfused with fixative containing $2 \%$ paraformaldehyde (PFA) and $0.2 \%$ glutaraldehyde, as described previously (Mironov et al., 2003). Brains were then collected, postfixed in the same fixative for 16-24 h, transferred to 1\% PFA in PHEM buffer (25 mM HEPES, 10 mM EGTA, 60 mM PIPES, $2 \mathrm{~mm} \mathrm{MgCl}_{2}, \mathrm{pH}$ 7.2) for $7 \mathrm{~d}$ and then stored in $0.5 \%$ PFA in PHEM.

Reagents and antibodies. Fab R2 was derived from phage libraries (Williamson et al., 1998) and binds to C-terminal residues 225-231 (Peretz et al., 1997). Mouse monoclonal antibody F4-31 IgG was raised against recombinant $\mathrm{PrP}$ of bovine sequence 101-241. It recognizes a nonlinear, discontinuous epitope in $\operatorname{PrP}^{\mathrm{C}}$, and does not bind to native $\operatorname{PrP}^{\mathrm{Sc}}(\mathrm{L} . \mathrm{H}$. Stanker, A. V. Servan, E. Cleveland, R. Hnasko, J. Safar, S. J. DeArmond, and S. B. Prusiner, unpublished observations). Rat anti-LAMP1 (BD Biosciences; PharMingen), anti-syntaxin 13 (Prekeris et al., 1998), mouse monoclonal anti-synaptobrevin/VAMP 2 (Synaptic Systems), and rabbit anti-MAP-2 (Abcam) were used as markers of late endosomes/lysosomes, early/recycling endosomes, axons and dendrites, respectively. Rabbit anti-GFAP (BIOTREND) and rabbit anti-glutamine synthetase (Sigma) were used as markers of astrocytes. Rabbit antimouse Fab was obtained from Pierce, and rabbit anti-mouse IgG and rabbit anti-rat IgG were from DAKOCytomation. Protein A-gold conjugate was obtained from Utrecht Medical Center. Fluorescent secondary antibodies, goat anti-mouse IgG coupled to Alexa Fluor 488 and goat anti-rabbit IgG coupled to Texas Red were from Invitrogen.

Thioflavin-S labeling for amyloid plaques. Thioflavin-S labeling was performed essentially as published (Sun et al., 2002). In brief, brain tissues from animals killed at $113 \mathrm{dpi}$ were processed through a Tissue TEK VIP processor (Sakura Finetek) and embedded in paraffin wax. Sections were cut on a rotary microtome, HM355 (Microm) at $8 \mu \mathrm{m}$ thickness, and were deparaffinized, rinsed in distilled water, and stained for $8 \mathrm{~min}$ with $0.05 \%$ Thioflavin-S (in the dark). Sections were then quickly flooded with distilled water to rinse off residual Thioflavin-S, before mounting with VectorShield with DAPI aqueous mount. Sections were viewed with a Leitz DMRB fluorescence microscope (JH Technologies) and micrographs were taken using an Olympus DP-70 digital camera. A section of brain tissue containing amyloid plaques was included in each labeling procedure as a positive control (supplemental Fig. 1, available at www.jneurosci.org as supplemental material).

Cryosectioning and immunolabeling. Blocks of tissue were embedded in gelatin, frozen in liquid nitrogen, and cryosectioned as described previously (Peters et al., 2006). Semithin sections (200 nm) for light microscopy were picked up from the diamond knife with $2.3 \mathrm{M}$ sucrose. Blocking, before the antibody incubations, was for $15 \mathrm{~min}$ in $1 \%$ BSA in PBSG (PBS containing $0.02 \mathrm{M}$ glycine). The F4-31 IgG and R2 Fab were de- tected using Alexa 488-conjugated goat anti-mouse IgG and rabbit antimouse Fab, followed by Alexa 488-conjugated goat anti-rabbit IgG, respectively. For double labeling of $\operatorname{PrP}$ and astrocytes, R2 Fab and rabbit anti-glutamine synthetase were detected using Alexa 488-conjugated, goat anti-mouse IgG and Texas Red-conjugated, goat anti-rabbit IgG, respectively. Controls omitting the primary antibodies and sections of $\operatorname{Prnp}{ }^{0 / 0}$ tissue labeled with anti-PrP antibodies consistently gave negative results. Labeled sections were examined using a Zeiss Axiovert $100 \mathrm{TV}$ inverted microscope. Micrographs were taken using a Photometrics Series 200 Black and White CCD camera, controlled by SmartCapture2 software, which adds false colors to the images. Ultrathin sections $(60 \mathrm{~nm}$ thick) were picked up using $1 \%$ methyl cellulose 25CP, $1.15 \mathrm{~m}$ sucrose solution and transferred to formvar/carbon-coated copper grids (hexagonal grid bars, spaced $200 \mu \mathrm{m}$ across). Sections were labeled for EM as described previously (Peters et al., 2006). Trypsin treatments were performed on EM grids after removal of the gelatin used for embedding, and washing with PBSG. Grids were floated on droplets of trypsin $(0.2 \%)$ in $20 \mathrm{~mm}$ Tris, $0.1 \% \mathrm{CaCl}_{2}, \mathrm{pH} 7.8$, for $7 \mathrm{~min}$ at $20^{\circ} \mathrm{C}$. After the treatment, grids were washed $3 \times 5$ s and then $5 \times 3$ min with PBSG, before blocking and antibody labeling. Labeled grids were examined using a Tecnai $12 \mathrm{G} 2$ electron microscope (FEI) at $80 \mathrm{kV}$. Hippocampal tissue from prioninfected animals showed a "looser" structure than that from uninfected animals, which could affect the accessibility of antibodies to the tissue. However, quantification of F4-31 labeling experiments suggested that this was not the case, as labeling levels on the two types of tissue were similar (see Table 2).

Quantification. Quantification of labeling was performed on areas selected by systematic random sampling. For the stratum oriens, starting close to a grid bar, micrographs were taken at regular intervals of a strip of tissue immediately adjacent to the pyramidal layer and $\sim 12 \mu \mathrm{m}$ wide. Blood vessels were avoided, because nonspecific labeling by the bridging antibodies often occurs. In the pyramidal layer, a strip of tissue extending from the stratum oriens to the stratum radiatum was used. Blocks from each of three control, three prion-infected, and two $\operatorname{Pr} n p^{0 / 0}$ brains were used. A grid of $P r n p^{0 / 0}$ tissue was included in each labeling reaction. The figures are based on data from one tissue block per brain, although other blocks were examined and found to give similar results. Gold particles that were labeling different subcellular structures were counted on micrographs with a final magnification of 11,000 , covering an area of 160 $\mu \mathrm{m}^{2}$ per brain for R2 and $104 \mu \mathrm{m}^{2}$ per brain for F4-31. Early endocytic/ recycling vesicles and late endosomes/lysosomes were identified using the endosomal markers syntaxin 13 (Prekeris et al., 1998) and LAMP1, respectively. In many cases, PrP labeling was found on small vesicles. Similar vesicles were labeled by the syntaxin 13 antibodies. Dendrites and axons were distinguished using MAP2 and VAMP2 as markers, respectively. On the basis of ultrastructural features associated with neuronal processes labeled by these antibodies, it was possible to distinguish "large" axons and dendrites (measuring > $250 \mathrm{~nm}$ in diameter). "Small" processes (of $<250 \mathrm{~nm}$ diameter) could not always be assigned to one of these categories with sufficient confidence so these structures were included as a separate class of small neurites. Other structures, i.e., Golgi, $\mathrm{ER}$, mitochondria, myelin, and synaptic junctions, were classified according to the criteria defined by Peters et al. (1991). Synaptic junctions were identified by the presence of presynaptic and postsynaptic membranes clearly displaying densities on their cytoplasmic faces, and with a synaptic cleft between them. These were counted to give the synapse numbers presented in Table 1.

A structure was considered to be labeled if a gold particle was located within $20 \mathrm{~nm}$. In some cases, gold particles could not be assigned to identifiable structures and these were designated as "other". Membranes of small vesicles can only be seen clearly if the plane of sectioning passes perpendicularly through them. It is likely that a number of gold particles classified as "other" were actually labeling early/recycling endosomes, so that labeling of this compartment was underestimated here. The total areas and numbers of gold particles examined in stratum oriens of infected brains were in line with previously published guidelines (Mayhew and Desoye, 2004). When a gold particle was found between closely apposed plasma membranes from neurites falling into two different classes (e.g., dendrite and axon), the gold label was counted as 0.5 for each class. Clusters of R2 immunogold 
Table 1. Labeling of synapses and PrPC in hippocampal sections of wild-type FVB mice

\begin{tabular}{llc}
\hline & Uninfected & Infected \\
\hline Synapse numbers $/ 100 \mu \mathrm{m}^{2}$ & $19.0 \pm 3.7$ & $6.9 \pm 1.6$ \\
$\operatorname{PrP}^{C}$ at synaptic junctions & $0.21 \pm 0.03$ & $0.25 \pm 0.18$ \\
$\operatorname{PrP}^{C}$ on all neuronal plasma membranes & $0.08 \pm 0.01$ & $0.07 \pm 0.04$ \\
\hline
\end{tabular}

Prion infection decreases the number of synapses but does not affect PrPC labeling by $\mathrm{F} 4-31{ }^{a}$

${ }^{a}$ Labeling density for $\operatorname{PrP}^{\mathrm{C}}$ was determined by the number of gold particles per $\mu \mathrm{m}$ of membrane length. Figures are \pm SD. There was no significant difference between uninfected and prion-infected hippocampus in the F4-31 labeling density on either synaptic junctions or on all neuronal plasma membranes. Synapse numbers were significantly reduced in the infected tissue $(p<0.001)$.

labeling in the stratum oriens were defined as at least three gold particles in an area of $0.25 \mu \mathrm{m}^{2}$. Since each primary antibody molecule could be labeled by more than one bridging antibody, we always counted pairs of gold particles located $<20 \mathrm{~nm}$ apart only once.

Background labeling was determined by counting gold particles on each compartment on the same number of micrographs of $\operatorname{Pr} n p^{0 / 0}$ hippocampus as were used for infected and control FVB mice. The average background label on each compartment was subtracted from the numbers obtained for prion-infected and mock-infected specimens to give values for specific labeling. Background labeling on astrocytes was derived from control labeling reactions in which the primary antibody was omitted. Background levels after trypsin treatments were determined by counting and averaging the numbers of gold particles detected in two experiments on trypsin-digested, hippocampal sections from Prnp $p^{0 / 0}$ mice (data not shown). Gold particles on mitochondria and lipid droplets were considered to be background, as described previously (Mayhew et al., 2002; Mironov et al., 2003).

Comparisons of labeling distributions (Tables 3, 4; supplemental Tables 1, 2, available at www.jneurosci.org as supplemental material) were performed using contingency-table analysis and calculation of $\chi^{2}$ values. Values were calculated for the numbers of gold particles expected to be found on each compartment of each group if the labeling distributions were the same. Expected values were calculated by the following equation:

(total gold particles in compartment for both groups) $\times$ (total gold particles observed for the group) total gold particles observed for both groups

For example, to determine the expected labeling in dendritic plasma membranes of uninfected samples, we calculate: (the sum of the gold particles observed on dendrite plasma membranes in uninfected and infected stratum oriens) $\times$ (total gold particles observed in uninfected stratum oriens) divided by (the grand total of gold particles counted in uninfected and infected stratum oriens).

The expected value was then compared with the observed labeling using the formula: (observed - expected) ${ }^{2} /$ expected. Deviations of the observed labeling from the expected values were then calculated as partial $\chi^{2}$ values. These indicate the degree by which the observed labeling deviates from the expected (Mayhew and Desoye, 2004).

For calculations of labeling density, the total lengths of each type of membrane (e.g., axonal plasma membrane or synaptic vesicle membrane) were estimated by counting all intersections of each membrane type with grid lines placed over the micrograph (Mayhew et al., 2002; Mayhew, 2005). Horizontal and vertical grid lines, $9.5 \mathrm{~cm}$ apart, were used in all cases except for synaptic junctions, where grid lines of $0.5 \mathrm{~cm}$ distance were used. The numbers of gold particles observed on each type of membrane were then related to the estimates of total length of membrane to give an estimate of labeling density.

Other statistical analyses were performed using binomial tests (comparison of gold counts on R2-labeled uninfected and Prnp ${ }^{0 / 0}$ stratum oriens, and numbers of synapses) and $\chi^{2}$ tests (comparison of labeling densities). A value of $p<0.05$ was used as a threshold for significance.

\section{Results}

Synapse loss and astrocytosis in hippocampal sections of FVB mice infected with RML prions

Infection of FVB mice with RML prions has previously been shown by immunolabeling at the light microscopic level to cause widespread $\mathrm{PrP}^{\mathrm{Sc}}$ accumulation throughout the cerebrum and brainstem, with high levels of $\mathrm{PrP}^{\mathrm{Sc}}$ in the hippocampus (DeArmond et al., 1997). In this study, we investigated the pathology and subcellular localization of PrP isoforms in hippocampal sections of RML-infected FVB mice by immunofluorescence and cryo-immunogold EM. The animals were killed $104-106 \mathrm{~d}$ postinoculation, before clinical signs of prion disease were apparent, to avoid nonspecific effects occurring in the late stages of neurodegeneration.

We found prominent astrocytosis and a $60 \%$ mean reduction in the number of synapses in hippocampal sections of infected FVB mice compared with uninfected controls (Table 1). Ultrathin cryosections of infected brains showed a looser structure (see Figs. 2, 3), which we attribute to changes resulting from the development of prion disease. Increased extracellular space has also been reported by EM of resin sections (Jeffrey et al., 2000). Thioflavin-S staining of prion-infected hippocampus revealed little amyloid formation, which is a nonobligatory feature of prion disease (DeArmond, 2004) (supplemental Fig. 1, available at www.jneurosci.org as supplemental material). Prion rods were also not observed.

\section{Localization of $\operatorname{PrP}^{\mathrm{C}}$ and $\operatorname{PrP}^{\mathrm{Sc}}$ to the neuropil by immunofluorescence}

Immunofluorescence was performed on semithin $(200 \mathrm{~nm}) \mathrm{sec}-$ tions of uninfected and prion-infected hippocampus, using the F4-31 monoclonal antibody that recognizes $\mathrm{PrP}^{\mathrm{C}}$ specifically (Stanker, Serban, Cleveland, Hnasko, Safar, DeArmond, and Prusiner, unpublished observations) and the R2 antibody fragment (fab) that recognizes an epitope in both $\operatorname{PrP}^{\mathrm{C}}$ and $\operatorname{PrP}^{\mathrm{Sc}}$ (Peretz et al., 1997). The labeling patterns obtained (Fig. 1) were similar to those reported previously by us for uninfected hippocampus using several antibodies (Mironov et al., 2003). The labeling was strongest in the neuropil of the stratum oriens and stratum radiatum and appeared punctate (Muramoto et al., 1992; Nailon and Ironside, 2000; Privat et al., 2000; Ryder et al., 2001), while the cell bodies of the pyramidal layer and the apical dendrites were not labeled. The R2 labeling of uninfected hippocampus was relatively weak. Labeling on prion-infected tissue was much stronger, as expected for an antibody that recognizes both $\operatorname{PrP}^{\mathrm{C}}$ and $\mathrm{PrP}^{\mathrm{Sc}}$. Hippocampal sections from $\operatorname{Pr} \mathrm{p}^{0 / 0}$ mice did not label with either antibody (Fig. 1) (data not shown). Cells with cytosolic PrP labeling observed previously in the pyramidal layer and stratum oriens of uninfected hippocampus (Mironov et al., 2003) were seen only rarely, and were not increased in abundance as a result of prion infection and therefore disregarded in the current study. Double labeling of sections with R2 and a marker of astrocytes (anti-glutamine synthetase) indicated that $\operatorname{PrP}$ is predominantly neuronal (Fig. $1 F$ ).

\section{Cryo-immunogold EM for PrP: prion infection increases total PrP but not PrP}

To determine the subcellular localization of $\operatorname{PrP}^{\mathrm{C}}$ and $\operatorname{PrP}^{\mathrm{Sc}}$ and to monitor changes in the levels of these PrP isoforms resulting from prion infection, the F4-31 and R2 antibodies were used to label the CA1 region of the hippocampus of three prion-infected, three uninfected, and two Prnp ${ }^{0 / 0}$ brains by cryo-immunogold EM. Quantitative analysis of the labeling in the stratum oriens was then performed. The stratum oriens, comprised mainly of neuropil, is located on the cortical side of the pyramidal cell layer. This region was chosen for analysis because the tissue is fairly homogeneous and the labeling by immunofluorescence was relatively high. 
Cryo-immunogold EM labeling using F4-31 antibody showed that $\operatorname{PrP}^{\mathrm{C}}$ levels did not increase as a result of prion infection (Table 2). R2 labeled $\mathrm{PrP}^{\mathrm{C}}$ only weakly compared with F4-31, but the amount of gold labeling was significantly above background levels seen in control samples without primary antibody and from $\operatorname{Prn}^{0 / 0}$ brain $(p<0.001)$. Specific R2 labeling increased 5.6-fold in prioninfected brain compared with normal brain (Table 2). As seen by light microscopy, most of the PrP detected by cryoimmunogold EM was present in the neuropil in both uninfected and prioninfected hippocampus. Most of this $\operatorname{PrP}$ was present on plasma membranes and small vesicles, particularly on small neurites (Fig. 2).

\section{Use of markers to identify \\ subcellular structures}

To facilitate the quantification of the cryoimmunogold EM labeling of PrP on different structures, cryo-immunogold EM was also performed using markers for axons, dendrites and astrocytes as well as for several subcellular structures. An antibody directed against VAMP2 labels synaptic vesicles and served as a marker for unmyelinated axons and axon terminals (Fig. 3A). Dendrites were recognized using an antibody to MAP2 (Fig. 3B). Immunolabeling with these two antibodies showed that large axons and dendrites (measuring $>250 \mathrm{~nm}$ in diameter) could be reliably identified on the basis of ultrastructural features. This was not always possible, however, for some of the smaller neurites. Therefore small neurites were treated as a separate category in the quantification of PrP labeling described below. Astrocytes were identified using GFAP and glutamine synthetase as markers (Fig. $1 F$ ) (data not shown).

Two antibodies were used to identify endocytic vesicles in the hippocampus: anti-syntaxin 13, a marker for early endocytic/recycling vesicles (Prekeris et al., 1998); and antiLAMP1, which recognizes late endosomes and lysosomes. In the strip of stratum oriens neuropil immediately adjacent to the pyramidal layer, the LAMP1 antibody mainly labeled structures resembling transitional early late endosomes (Fig. $3 E$ ). As expected, late endosomes, multivesicular bodies and lysosomes were found infrequently in this region, and were more common in the cell bodies of the pyramidal layer. Anti-syntaxin 13 mainly labeled vesicles that had no obvious internal membranes and were smaller than the LAMP1-positive vesicles but larger than synaptic vesicles. These vesicles were predominantly found in dendrites and close to axon terminals. Syntaxin 13 labeling was sometimes found on tubular structures, probably recycling endosomes, which have been described in both axons and dendrites. Anti-syntaxin 13 also labeled the transitional early late endosome-like structures recognized by the LAMP1 antibody (Fig. 3C,D). Our observations of endocytic vesicles are in

\section{Table 2. Cryo-immunogold EM for PrP}

\begin{tabular}{lcll}
\hline Label (average per $100 \mu \mathrm{m}^{2} \pm$ SD) & Uninfected & $\begin{array}{l}\text { Prion- } \\
\text { infected }\end{array}$ & Prnp \\
\hline F4-31 & $144 \pm 38$ & $120 \pm 70$ & $10 \pm 1$ \\
R2 & $27 \pm 9$ & $101 \pm 12$ & $11 \pm 6$
\end{tabular}

Labeling of $\mathrm{PrP}^{\mathrm{C}}+\mathrm{PrP}^{\mathrm{Sc}}$ by $\mathrm{R} 2$ increases in prion-infected stratum oriens. After subtraction of the background labeling on Prnp ${ }^{0 / 0}$ hippocampus, the average change in specific labeling upon prion infection was found to be -1.2 -fold for $\mathrm{F} 4-31$ and +5.6 -fold for R2. Labeling of uninfected tissue by R2 and F4 - 31 was significantly above background ( $p<0.001$ for both antibodies). Labeling by R2 was higher in infected than uninfected hippocampus $(p<0.001)$, and F4-31 labeling was slightly lower in infected than uninfected tissue $(p=0.03)$.

agreement with previous reports for hippocampal neurons (Parton et al., 1992; Mundigl et al., 1993; Prekeris et al., 1999).

In contrast to anti-VAMP2 and anti-MAP2 labeling, the F4-31 and R2 antibodies to PrP gave relatively low levels of cryoimmunogold EM labeling in the hippocampus. However, by analyzing a sufficiently large number of gold particles, an informa- 
F4-31 anti-PrPC
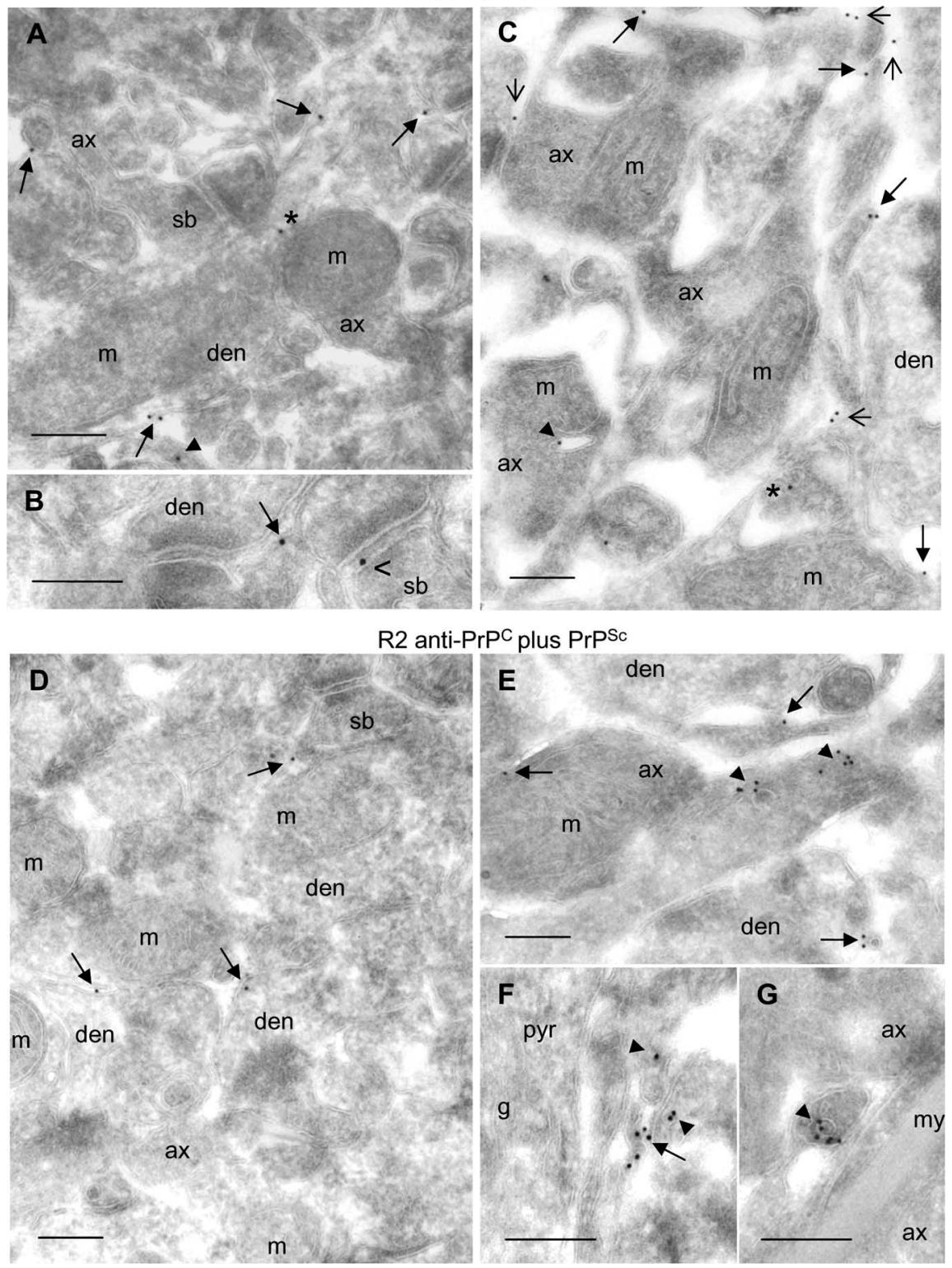

Figure 2. Cryo-immunogold EM labeling of PrP in the hippocampus of uninfected and prion-infected mice. Note that membranes appear white using this method. $A-C, \operatorname{PrP}^{C}$ labeled by F4-31. D-G, $\operatorname{PrP}^{C}$ and $\operatorname{PrP}^{\mathrm{SC}}$ labeled by R2. Stratum oriens of uninfected $(\boldsymbol{A}, \boldsymbol{B}, \boldsymbol{D})$ and prion-infected $(\boldsymbol{C}, \boldsymbol{E}-\boldsymbol{G})$ mice. Clusters of $\mathrm{R} 2$ label are evident on vesicles or tubules $(\boldsymbol{E}, \boldsymbol{G})$ and on the plasma membrane $(\boldsymbol{F})$ of small neurites. Closed arrows indicate plasma membrane labeling; arrowheads point to gold particles on early endocytic/recycling vesicles; open arrows indicate extracellular label. Asterisk in $A$ indicates $P r P C$ on a gold particle that is not visibly membrane-associated. In $\boldsymbol{B}$, the open arrowhead $(<)$ indicates a labeled synaptic junction. Asterisk in $\boldsymbol{C}$ indicates a gold particle associated with a multivesicular body. ax, Axon; den; dendrite; $g$, Golgi apparatus; $m$, mitochondrion; my, myelin; pyr, pyramidal cell body; sb, synaptic bouton. Scale bars, $200 \mathrm{~nm}$.

tive picture of the labeling distribution could be assembled. Furthermore, the inclusion of hippocampal samples from $\operatorname{Prnp}{ }^{0 / 0}$ mice in all labeling experiments ensured that only prionspecific labeling was measured.

\section{Cryo-immunogold EM for $\operatorname{PrP}^{\mathrm{C}}$ using antibody F4-31}

We first compared the immunogold labeling distributions of anti-PrP ${ }^{\mathrm{C}}$ antibody, $\mathrm{F} 4-31$, in the stratum oriens of scrapieinfected and uninfected hippocampus. As seen in Figure 4 showing the average numbers of gold particles found on different subcellular compartments, most of the labeling was found on plasma membranes in both the uninfected and infected tissue (Fig. 4, DP,
$\mathrm{XP}, \mathrm{snP})$, with a majority on small neurites (Fig. 4, snP). Gold label was also found on structures resembling early endocytic/recycling vesicles and occasionally on transitional early late endosomes, late endosomes and synaptic vesicles. Extracellular $\operatorname{PrP}^{\mathrm{C}}$ was also detected.

\section{$\operatorname{PrP}^{\mathrm{C}}$ labeling is reduced on dendrites and increased extracellularly in prion- infected hippocampus}

Using contingency table analysis, which is a simple method for drawing betweengroup comparisons of labeling distributions (Mayhew and Desoye, 2004), we compared the F4-31 labeling distributions in uninfected and prion-infected stratum oriens. For this, we calculated the numbers of gold particles that we would expect to find on each subcellular compartment of uninfected and infected hippocampus, if the labeling distributions were the same. Deviations of the observed labeling from the expected values were then calculated as partial $\chi^{2}$ values. A large compartmental $\chi^{2}$ value indicates a large deviation from the expected number. We found the distribution of F4-31 labeling on uninfected tissue to be statistically different from that on prion-infected tissue $(p<0.001)$ (Table 3$)$. The figures indicated that the amount of labeling on both plasma membranes and early endocytic/ recycling vesicles of dendrites was reduced in infected hippocampus compared with the healthy tissue. Differences in the amount of dendrite plasma membrane and endocytic vesicle membrane in the infected hippocampus were insufficient to account for the decreases in PrP labeling observed (data not shown). In contrast, we observed a much higher than expected level of extracellular labeling in prioninfected hippocampus compared with that of uninfected hippocampus, suggesting that $\mathrm{PrP}^{\mathrm{C}}$ may be released from the plasma membrane as a consequence of prion infection. Synaptic vesicles in infected tissue also had a slightly higher amount of labeling than the calculated expected values. Interestingly, prion infection was not found to affect the proportion of gold label binding to the plasma membrane of small neurites, although this compartment showed the largest amount of gold labeling, both in uninfected and infected tissue. Similarly, labeling of endocytic vesicles showed little change between uninfected and infected samples (Fig. 4, Table 3). Because astrocytes are much less abundant in normal brains, we observed a greater than expected labeling of astrocytes in infected brains. The total number of gold particles on astrocytes was small. However, together with unpublished observations of control incubations in which the primary antibody was omitted, our data agree with previous reports that $\mathrm{PrP}^{\mathrm{C}}$ is present on astrocytes (Table 3) (Kovács et al., 2005). 
In a previous study on normal hippocampus, anti-PrP antibodies showed relatively little binding to synaptic vesicles and the labeling density at synaptic junctions was found to be similar to that on other types of plasma membrane (Mironov et al., 2003). Using the high-affinity antibody, F4-31, little labeling was found on synaptic vesicles in normal hippocampus, and there was no clear increase in infected hippocampus (Fig. 4, Table 3). We also analyzed the labeling density at synaptic junctions, where the apposed axonal and dendritic plasma membranes are separated by a synaptic cleft. We found a 2 to 3 times higher labeling density at these sites in both uninfected and infected sections compared with the labeling on the plasma membranes of all neurites (Table 1).

\section{Cryo-immunogold EM for $\operatorname{PrP}^{\mathrm{C}}$ and $\operatorname{PrP}^{\mathrm{Sc}}$ using antibody R2}

The $\mathrm{R} 2$ antibody, which recognizes native $\mathrm{PrP}^{\mathrm{Sc}}$ in addition to $\mathrm{PrP}^{\mathrm{C}}$ (Peretz et al., 1997), was used to assess whether PrP is present in prion-infected hippocampus at sites where $\operatorname{PrP}^{\mathrm{C}}$ was not detected, and to look for regions where $\mathrm{PrP}^{\mathrm{Sc}}$ may be concentrated. As with F4-31, the R2 labeling seen by cryo-immunogold EM in the stratum oriens was found principally on the plasma membrane and in small diameter endocytic vesicles of the neuropil (Figs. 2, 5). Of the various subcellular compartments, small neurites of infected brains showed the greatest average numbers of gold particles (Fig. $5 a$ ). Membranes of these small neurites also showed the greatest labeling density (number of gold particles per $\mu \mathrm{m}$ membrane) (Fig. $5 b$ ) and the biggest increases in labeling density after infection. The early endocytic/recycling endosomes showed a 24-fold increase and plasma membranes, an eightfold increase. Consistent with immunofluorescence data (Fig. 1), labeling of pyramidal cell bodies was close to the background levels found on sections of $\operatorname{Prnp}{ }^{0 / 0}$ hippocampus. We found no evidence that pyramidal cell bodies accumulated PrP in the ER, Golgi or in lysosomes in either uninfected or prion-infected hippocampus (S. Godsave and P. Peters, unpublished data). R2 labeling showed a general increase in the neuropil of prion-infected hippocampus. In these samples, we also observed clusters of labeling, which were defined as three or more gold particles located within a $250 \mathrm{~nm}^{2}$ area. One-fifth $(20 \pm 6.1 \%)$ of the total gold particles in infected hippocampus was found in clusters. In the stratum oriens, we found five clusters $(5.2 \pm 1.3)$ per $100 \mu \mathrm{m}^{2}$ in infected samples, but none in uninfected tissue. Of the clustered label, 100\% was found associated with neuronal processes with a diameter $<750 \mathrm{~nm}$, and $>50 \%$ was in small neuronal cell processes with a diameter $<250 \mathrm{~nm}$. Clustered gold was mostly found on the PM or on early endocytic/recycling vesicles or tubules. In agreement with previous reports (Jeffrey et al., 2004), we also occasionally saw clusters of label in lysosomes of astrocytes (data not shown). No PrP clusters were detected in neuronal lysosomes.

Because prion infection has been shown to reduce the number of synapses (Jeffrey et al., 2000; Bouzamondo-Bernstein et al., 2004), we investigated whether $\operatorname{PrP}^{\mathrm{Sc}}$ accumulates at synaptic

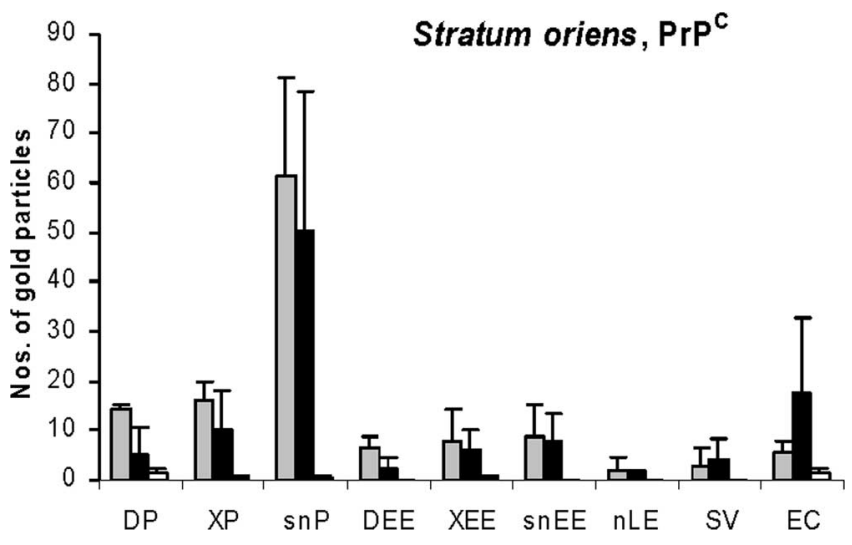

Figure 4. Quantification of $\operatorname{PrP}^{\mathrm{C}}$ labeling by $\mathrm{F} 4-31$ in uninfected, prion-infected and Prnp ${ }^{0 / 0}$ stratum oriens. Numbers of gold particles labeling different compartments per 100 $\mu \mathrm{m}^{2}$ of stratum oriens. Average of counts from three uninfected brains (gray bars), three prion-infected brains (black bars) and three labeling reactions on two Prnp ${ }^{0 / 0}$ brains (white bars). Error bars indicate SDs. A large proportion of the gold labeling was found on plasma membranes (PM), particularly of small neurites. DP, PM of large dendrites; XP, PM of large axons; snP, PM of small neurites; DEE, early endocytic/recycling endosomes (EE) of large dendrites; XEE, EE of large axons; snEE; EE of small neurites. nLE; late endosomal or transitional early late endosomal vesicles of neurons (all sizes); SV, synaptic vesicles; EC, extracellular.

junctions, where it might be able to exert its toxic effects. Interestingly, labeling by the R2 antibody was only rarely found at synaptic junctions in both normal and prion-infected hippocampus, and clusters of label were never found at these sites. Furthermore, the amount of labeling on synaptic vesicles remained small in prion-infected tissue (Fig. 5, Table 4) (data not shown). 
Table 3. Analysis of the distribution of F4-31 labeling shows reduced labeling of dendrites in prion-infected stratum oriens

\begin{tabular}{|c|c|c|c|c|c|c|c|}
\hline \multirow[b]{2}{*}{ Compartment } & \multicolumn{2}{|c|}{ Uninfected } & \multicolumn{2}{|c|}{ Prion-infected } & \multirow[b]{2}{*}{ Row totals } & \multicolumn{2}{|l|}{$\chi^{2}$} \\
\hline & Observed & Expected & Observed & Expected & & Uninfected & Prion-infected \\
\hline Large dendrite PM & 42.5 & 31.4 & 15.0 & 26.1 & 57.5 & 3.9 & 4.7 \\
\hline Large axon PM & 49.0 & 43.7 & 31.0 & 36.3 & 80.0 & 0.7 & 0.8 \\
\hline Small neurite PM & 183.5 & 182.5 & 151.0 & 152.0 & 334.5 & 0.0 & 0.0 \\
\hline Large dendrite EE & 20.0 & 14.7 & 7.0 & 12.3 & 27.0 & 1.9 & 2.3 \\
\hline Large axon EE & 24.0 & 22.9 & 18.0 & 19.1 & 42.0 & 0.1 & 0.1 \\
\hline Small neurite EE & 27.0 & 27.3 & 23.0 & 22.7 & 50.0 & 0.0 & 0.0 \\
\hline Neuronal LE & 6.0 & 5.5 & 4.0 & 4.5 & 10.0 & 0.1 & 0.1 \\
\hline Synaptic vesicle & 8.0 & 11.5 & 13.0 & 9.5 & 21.0 & 1.0 & 1.3 \\
\hline Astrocyte & 0.0 & 6.5 & 12.0 & 5.5 & 12.0 & 6.5 & 7.9 \\
\hline Extracellular & 17.0 & 37.7 & 52.0 & 31.3 & 69.0 & 11.3 & 13.6 \\
\hline Mitochondrion & 9.0 & 9.3 & 8.0 & 7.7 & 17.0 & 0.0 & 0.0 \\
\hline Other & 74.0 & 67.1 & 49.0 & 55.9 & 123.0 & 0.7 & 0.8 \\
\hline Total & 460.0 & & 383.0 & & 843.0 & 26.2 & 31.5 \\
\hline
\end{tabular}

Combined data from three labeling experiments on infected and uninfected brains are shown. Labeling by cryo-immunogold EM was quantified as described in Materials and Methods. Background labeling on mitochondria is included in the table. All membrane-bound labeling on astrocytes was included in one category. Row totals represent the total labeling observed for each compartment. The total sum of the partial $\chi^{2}$ values (57.7) is related to the degree of difference between the two groups. For 12 compartments and two groups, the degrees of freedom for the summed partial $\chi^{2}$ values were $(12-1) \times(2-1)=11$. For F4 -31 labeling of uninfected and infected hippocampus, the two distributions were found to be significantly different $(p<0.001$ for 11 degrees of freedom). EE, early endosome; LE, late endosome.
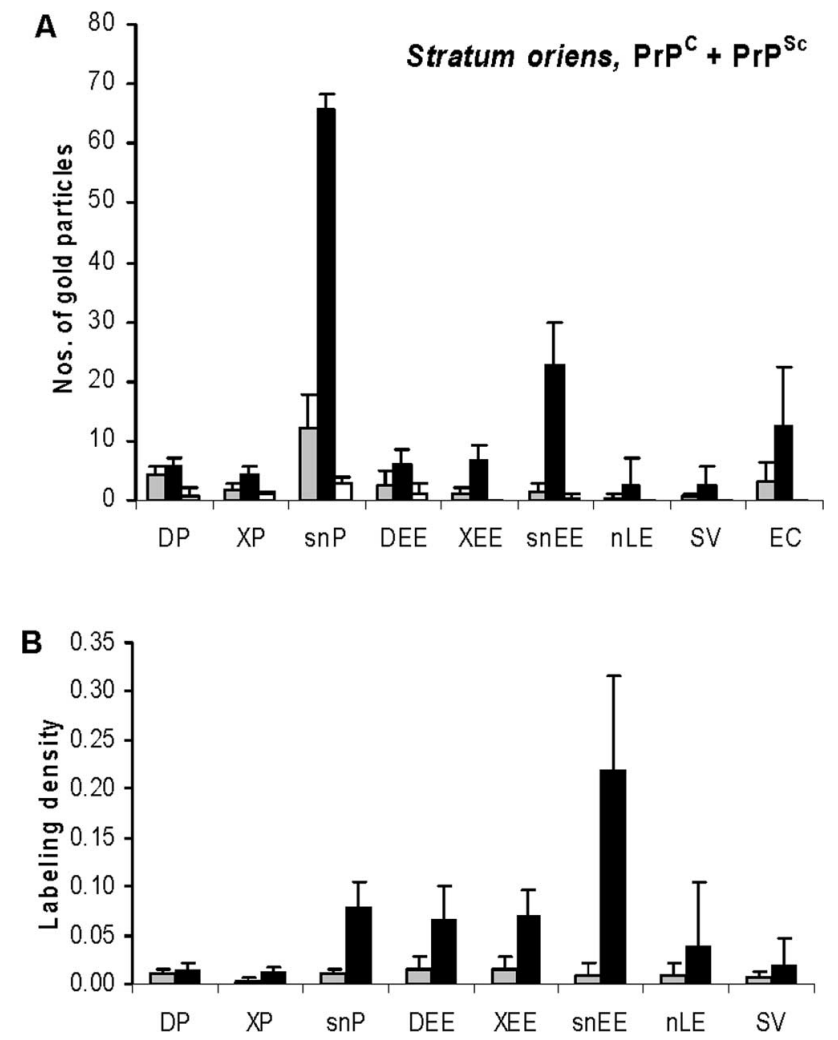

Figure 5. Quantification of $\mathrm{PrPC}^{\mathrm{C}}$ and $\mathrm{PrP} \mathrm{P}^{\mathrm{Sc}}$ labeling by $\mathrm{R} 2$ in uninfected, prion-infected and Prnp ${ }^{0 / 0}$ stratum oriens. $A$, Numbers of gold particles labeling different compartments per $100 \mu \mathrm{m}^{2}$ of stratum oriens. $\boldsymbol{B}$, Labeling density on different classes of membrane. The figures are the averages of counts from three uninfected brains (gray bars), three prion-infected brains (black bars) and three labeling reactions on two $P r n p{ }^{0 / 0}$ brains. In $A$, the $P r n p^{0 / 0}$ data are shown by white bars. In $\boldsymbol{B}$, the data for uninfected and prion-infected tissue are shown after subtraction of the background labeling levels determined on $P r n p^{0 / 0}$ tissue for each compartment. Labeling density was determined as the number of gold particles per micrometer of membrane. Approximately sixfold more antibody labeling was seen in the prion-infected tissue compared with the uninfected tissue. Most of the gold particles were found on plasma membranes and early endocytic/recycling vesicles of small neurites. The labeling density was highest on endosomal vesicles of small neurites. Error bars indicate SDs. Abbreviations are as indicated in the legend to Figure 4.

Increased R2 labeling on small neurites in prion-infected hippocampus

Statistical analysis of R2 labeling between infected and uninfected tissue indicated that prion infection significantly affected the dis- tribution of gold label in the hippocampus $(p<0.001)$ (Table 4$)$. The number of gold particles nonspecifically labeling mitochondria was unaffected by prion infection, while specific labeling increased. This resulted in large differences in the proportions of the total label that were detected on mitochondria and in high partial $\chi^{2}$ values. The biggest increases in specific labeling in prion-infected tissue were found on the early endocytic/recycling vesicles and on plasma membranes of small neurites, suggesting that these neurites may be particularly important in prion disease (Table 4). In contrast, the R2 label observed on plasma membranes of dendrites was substantially higher in uninfected stratum oriens than expected. Interestingly, higher than expected labeling of dendritic plasma membranes in normal hippocampus were found with both R2 and F4-31 (Table 3). The density of R2 labeling on dendrite PM also failed to increase significantly following infection by prions (Fig. 5b), suggesting that $\mathrm{PrP}^{\mathrm{Sc}}$ may not accumulate on large dendritic profiles (i.e., $>250 \mathrm{~nm}$ ).

Contingency table analysis was also used to compare the distributions of R2 and F4-31 labeling. We found no significant difference between the two labeling distributions in uninfected hippocampus, although labeling by R2 was found to be relatively low on the plasma membranes of large axons and relatively high extracellularly. No overall difference was expected since only $\mathrm{PrP}^{\mathrm{C}}$ is present in this tissue (supplemental Table 1 , available at www.jneurosci.org as supplemental material). In contrast, the F4-31 and R2 labeling distributions in prion-infected hippocampus were significantly different $(p<0.001)$ (supplemental Table 2 , available at www.jneurosci.org as supplemental material). The R2 labeling was again relatively low on large axons. Early endocytic/recycling vesicles of small neurites were relatively highly labeled by R2, suggesting again that these structures might be sites of $\mathrm{PrP}^{\mathrm{Sc}}$ accumulation.

\section{Labeling of $\operatorname{PrP}^{\mathrm{C}}$ and $\operatorname{PrP}^{\mathrm{Sc}}$ by $\mathrm{R} 2$ is trypsin sensitive}

Because a high proportion of $\mathrm{PrP}^{\mathrm{Sc}}$ in prion-infected tissues has been shown to be protease sensitive (Safar et al., 1998, 2005b; Pastrana et al., 2006), we investigated the protease sensitivity of $\mathrm{PrP}^{\mathrm{Sc}}$ in the infected brain sections used in our study. Because proteinase $\mathrm{K}(\mathrm{PK})$ damaged the sections even after short digestion periods with low protease concentrations (data not shown), we chose to use trypsin, which has also been used to digest $\mathrm{sPrP} \mathrm{P}^{\mathrm{Sc}}$ (Pastrana et al., 2006). Here, ultrathin hippocampal cryosections on EM grids were treated with trypsin before addition of the R2 
Table 4. Analysis of the distribution of R2 labeling shows increased labeling on "small" neurites and relatively low labeling on dendrites in prion-infected stratum oriens

\begin{tabular}{|c|c|c|c|c|c|c|c|}
\hline \multirow[b]{2}{*}{ Compartment } & \multicolumn{2}{|c|}{ Uninfected } & \multicolumn{2}{|c|}{ Prion-infected } & \multirow[b]{2}{*}{ Row totals } & \multicolumn{2}{|l|}{$\chi^{2}$} \\
\hline & Observed & Expected & Observed & Expected & & Uninfected & Prion-infected \\
\hline Large dendrite PM & 12.5 & 6.4 & 17.5 & 23.6 & 30 & 5.8 & 1.6 \\
\hline Large axon PM & 5 & 3.7 & 12.5 & 13.8 & 17.5 & 0.4 & 0.1 \\
\hline Small neurite PM & 36.5 & 49.9 & 197 & 183.6 & 233.5 & 3.6 & 1.0 \\
\hline Large dendrite EE & 8 & 5.6 & 18 & 20.4 & 26 & 1.1 & 0.3 \\
\hline Large axon EE & 3 & 4.9 & 20 & 18.1 & 23 & 0.7 & 0.2 \\
\hline Small neurite EE & 4 & 15.4 & 68 & 56.6 & 72 & 8.4 & 2.3 \\
\hline Neuronal LE & 1 & 1.9 & 8 & 7.1 & 9 & 0.4 & 0.1 \\
\hline Synaptic vesicle & 2 & 2.1 & 8 & 7.9 & 10 & 0.0 & 0.0 \\
\hline Astrocyte & 0 & 1.3 & 6 & 4.7 & 6 & 1.3 & 0.3 \\
\hline Extracellular & 10 & 10.0 & 37 & 37.0 & 47 & 0.0 & 0.0 \\
\hline Mitochondrion & 30 & 14.3 & 37 & 52.7 & 67 & 17.2 & 4.7 \\
\hline Other & 19 & 15.4 & 53 & 56.6 & 72 & 0.8 & 0.2 \\
\hline Total & 131 & & 482 & & 613 & 39.8 & 10.8 \\
\hline
\end{tabular}

Quantification and analysis of the labeling distributions were performed as described in Materials and Methods and Table 3 legend. The same number of images of uninfected as prion-infected hippocampus were analysed, but PrP levels were higher in the infected hippocampus. The R2 antibody has a lower affinity for PrP than F4-31, and the gold counts were also lower. The total $\chi^{2}$ value for R2 labeling was 50.6 , and the two distributions were found to be significantly different $(p<0.001$ for 11 degrees of freedom). All labeling was included in the analysis shown. However, the difference between the distributions was also highly significant $(p<0.001)$ if the numbers for mitochondria and myelin (included in the category "Other") were excluded from the analysis (data not shown).

\section{Protease sensitivity of PrP}

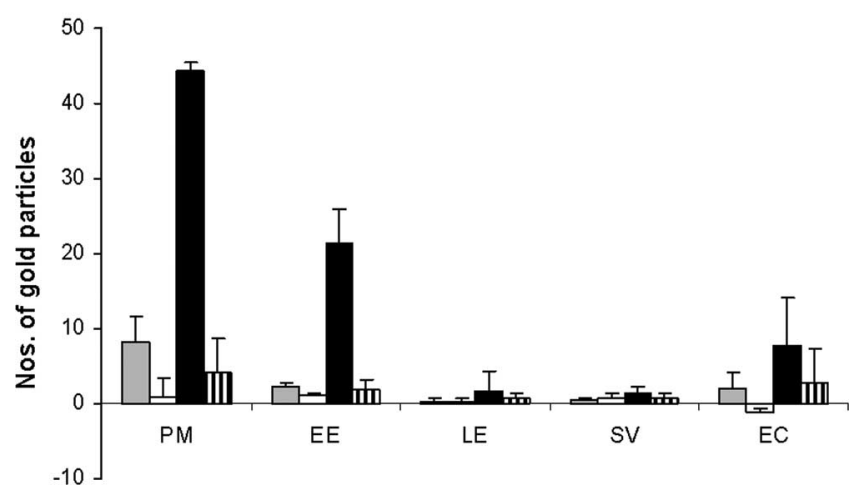

Figure 6. Quantification of PrP labeling by R2 before and after trypsin treatment of uninfected and prion-infected stratum oriens. Numbers of gold particles per $100 \mu \mathrm{m}^{2}$ of stratum oriens are shown after subtraction of background labeling levels determined on Prnp ${ }^{0 / 0}$ tissue. The figures are the averages of counts from three uninfected brains (gray bars, untrypsinized; white bars, trypsin-treated) and three prion-infected brains (black bars, untrypsinized; striped bars, trypsin-treated). Less than $15 \%$ of the labeling remained after trypsin treatment. Error bars indicate SDs. EE, Early endosomal/recycling vesicles; LE, late endosomes/lysosomes; SV, synaptic vesicles; EC, extracellular.

antibody. More than $85 \%$ of the $\mathrm{R} 2$ epitope was found to be trypsin sensitive both in the uninfected and the infected tissue, indicating that the majority of tissue-bound $\mathrm{PrP}^{\mathrm{Sc}}$ remains protease sensitive (Fig. 6).

\section{Discussion}

Increased $\mathrm{PrP}^{\mathrm{Sc}}$ in the hippocampus of presymptomatic prion-infected mice

In this study, we investigated the subcellular PrP distribution in the CA1 region of prion-infected murine hippocampus, at $\sim 90 \%$ of the disease incubation period. The main diagnostic feature of prion disease is an increase in $\mathrm{PrP}^{\mathrm{Sc}}$, which has a longer half-life than $\operatorname{PrP}^{\mathrm{C}}$ (Borchelt et al., 1992). We found approximately sixfold higher R2 labeling ( $\operatorname{PrP}^{\mathrm{C}}$ plus $\left.\mathrm{PrP}^{\mathrm{Sc}}\right)$ in the infected hippocampus than in uninfected hippocampus. In agreement with previous studies on brain (Oesch et al., 1985) and cultured cells (Caughey et al., 1989), there was no increase in the amount of $\operatorname{PrP}^{\mathrm{C}}$, as detected by the F4-31 antibody. We therefore assume that the additional R2 labeling in the infected brains was due to $\operatorname{PrP}^{\mathrm{Sc}}$ and not $\operatorname{PrP}^{\mathrm{C}}$. A sixfold increase in $\operatorname{PrP}$ was previously shown to be sufficient to cause prion disease. Syrian hamsters infected with eight different prion strains showed three to tenfold increases in PrP levels at clinical disease stages (Safar et al., 1998).

\section{Advantages of cryo-immunogold EM for prion detection}

Our results for uninfected hippocampus were similar to those of our previous cryo-immunogold EM study of uninfected tissue in which $\operatorname{PrP}^{\mathrm{C}}$ was detected on the plasma membranes of axons and dendritic shafts and spines, as well as at synaptic junctions. Label was also found in endocytic vesicles, and at a lower level on synaptic vesicles (Mironov et al., 2003). Previous immuno-EM studies of prion-infected brains indicated $\mathrm{PrP}^{\mathrm{Sc}}$ at synapses and in neuronal lysosomes (Grigoriev et al., 1999; Fournier et al., 2000). PrP was also found in lysosomes of prion-infected cultured cells and "fractionated brain" (McKinley et al., 1991; Arnold et al., 1995), but we did not find any clear increase in PrP at these sites in prion-infected murine hippocampus. Our results were consistent with other studies, which reported the presence of diseaseassociated PrP extracellularly, on neuronal plasma membranes and in astrocytic lysosomes of murine, prion-infected brain (Jeffrey et al., 1994, 2004). We additionally found disease-associated $\mathrm{PrP}$ in endocytic vesicles of neurons. The cryo-immunogold EM technique used here, using the $\mathrm{R} 2$ antibody to detect native $\mathrm{PrP}^{\mathrm{Sc}}$, should be more sensitive and less prone to nonspecific labeling than other immuno-EM techniques, which require more aggressive processing methods and often need denaturation treatments to expose epitopes in $\mathrm{PrP}^{\mathrm{Sc}}$. Use of $\operatorname{Prnp}^{0 / 0}$ brains as a control in all experiments further ensured that we observed specific labeling.

Early endocytic-recycling vesicles of small neurites are sites of $\operatorname{PrP}^{\mathrm{Sc}}$ accumulation

Most PrP immunoreactivity in prion-infected hippocampus was found in the neuropil in small neurites $<250 \mathrm{~nm}$ diameter, whereas very little was seen in pyramidal cell bodies. At the subcellular level, most of the $\operatorname{PrP}^{\mathrm{C}}$ labeling by F4-31, and of $\operatorname{PrP}^{\mathrm{C}}$ plus $\mathrm{PrP}^{\mathrm{Sc}}$ by $\mathrm{R} 2$, were present on plasma membranes, and both dendrites and axons were labeled. We also frequently found F4-31 and R2 labeling of small vesicles (Figs. 2, 4, 5). Labeling studies with anti-syntaxin 13 suggested that many of these were early endocytic/recycling vesicles (Fig. 3). Statistical analysis using contingency tables to compare labeling distributions confirmed that there was disproportionately high R2 labeling in these 
early endocytic/recycling vesicles of small neurites in the prioninfected hippocampus (Table 4; supplemental Table 2, available at www.jneurosci.org as supplemental material). They also showed the highest R2 labeling density (Fig. 5b). Furthermore, clusters of R2 labeling in the stratum oriens of infected hippocampus were frequently found on the plasma membranes and small vesicles of small neurites.

It has been reported that $\operatorname{PrP}^{\mathrm{C}}$ must traffic to the plasma membrane and be internalized for conversion to $\mathrm{PrP}^{\mathrm{Sc}}$ in neuroblastoma cells. Enzymatic removal of $\mathrm{PrP}^{\mathrm{C}}$ from the plasma membrane or culturing cells at lower temperature to prevent internalization inhibited conversion (Caughey and Raymond, 1991; Borchelt et al., 1992). Our results are consistent with these data.

\section{Synapse loss in prion infection is not caused by $\mathrm{PrP}^{\mathrm{Sc}}$ at synaptic junctions}

One of the earliest pathological changes in infected brains is synapse loss. In C57BL mice infected with ME7 prions, a 30-40\% reduction in numbers of synapses was observed at $72 \%$ of the incubation period (Jeffrey et al., 2000). We detected $\operatorname{PrP}^{\mathrm{C}}$ at synaptic junctions in both uninfected and prion-infected hippocampus, but the labeling level was not significantly different (Table 1). No evidence was found for $\mathrm{PrP}^{\mathrm{Sc}}$ at synaptic junctions, or in synaptic vesicles. It therefore appears unlikely that $\operatorname{PrP}^{\mathrm{Sc}}$ acts directly on synapses.

\section{Neurodegeneration in prion disease: possible mechanisms}

The mechanisms of neurodegeneration in prion disease are not well understood. $\mathrm{PrP}^{\mathrm{Sc}}$ is toxic only in $\mathrm{PrP}^{\mathrm{C}}$-expressing cells (Brandner et al., 1996), possibly by perturbing ion flow or disrupting signaling processes. Our results would be consistent with either possibility.

Oligomers of various amyloid-forming proteins, including the PrP fragment spanning residues 106-126, are able to increase membrane permeability, allowing net entry of $\mathrm{Ca}^{2+}$ into cells (Demuro et al., 2005). In the GT1 hypothalamic cell line, prion infection disturbed $\mathrm{Ca}^{2+}$ homeostasis by disrupting the function of N-type calcium channels (Sandberg et al., 2004). Interestingly, $\mathrm{Ca}^{2+}$ influx may ultimately trigger degradation of cytoskeletal and membrane proteins, leading to axon degeneration (Coleman, 2005). Another possible cause of axonal degeneration is impaired axonal transport (Coleman, 2005), evidence of which has been found in CJD-affected brains (Liberski and Budka, 1999; Ferrer et al., 2000).

Increasing in vitro evidence indicates that $\mathrm{PrP}^{\mathrm{C}}$ plays a role in cell signaling. $\mathrm{PrP}^{\mathrm{C}}$ was found in caveolae in $\mathrm{CHO}$ cells expressing Syrian hamster $\operatorname{PrP}^{C}$ (Peters et al., 2003). Caveolin-1dependent coupling of $\operatorname{PrP}^{\mathrm{C}}$ to the tyrosine kinase Fyn was observed in the neuronal differentiation model, $1 \mathrm{C} 11$, and $\operatorname{PrP}^{\mathrm{C}}$ can modulate serotonergic receptor signaling and cross talk in differentiated cells (Mouillet-Richard et al., 2000, 2005). $\operatorname{PrP}^{\mathrm{C}}$ was shown to be involved in neurite outgrowth and synapse formation via mechanisms involving NCAM and Fyn (Schmitt-Ulms et al., 2001; Kanaani et al., 2005; Santuccione et al., 2005). Although it is not yet known whether prion infection affects these processes, evidence suggests that dendritic atrophy in prion disease could be caused by effects of $\mathrm{PrP}^{\mathrm{Sc}}$ on Notch-1 activation and signaling (Ishikura et al., 2005). Because we found a reduction in the amount of $\mathrm{PrP}^{\mathrm{C}}$ in large dendrites, a deleterious loss of function cannot be ruled out.

\section{Most $\operatorname{PrP}^{\mathrm{Sc}}$ is protease sensitive in RML-infected murine hippocampus}

Thioflavin-S staining revealed no amyloid in prion-infected hippocampus (supplemental Fig. 1, available at www.jneurosci.org as supplemental material). Furthermore, trypsin treatment of hippocampal sections reduced the amount of R2 immunoreactivity by $>85 \%$, both in uninfected and RML-infected stratum oriens (Fig. 6), indicating that a high proportion of the $\mathrm{PrP}^{\mathrm{Sc}}$ in this region may be protease sensitive. Upon conversion of $\mathrm{PrP}^{\mathrm{C}}$ to $\mathrm{PrP}^{\mathrm{Sc}}$, the $\mathrm{C}$ terminus of the protein can acquire resistance to PK (Cohen and Prusiner, 1998), and this feature is commonly used to distinguish $\operatorname{PrP}^{\mathrm{Sc}}$ from $\operatorname{PrP}^{\mathrm{C}}$. However, a substantial proportion of $\mathrm{PrP}^{\mathrm{Sc}}$ is $\mathrm{PK}$-sensitive, with acquisition of protease resistance correlating with increasing aggregate size (Safar et al., 1998, 2005b; Tzaban et al., 2002; Rezaei et al., 2005; Pastrana et al., 2006).

Turnover and clearance of prions from the brain were monitored in a study on RML prion-infected transgenic mice in which PrP expression could be regulated by doxycycline. At almost all time-points throughout the incubation period, $\mathrm{sPrP}^{\mathrm{Sc}}$ was the predominant form, although the proportion of proteaseresistant $\operatorname{PrP}^{\mathrm{Sc}}\left(\mathrm{rPrP}^{\mathrm{Sc}}\right)$ increased with time. In the same study, $\mathrm{PK}$-treated histoblots revealed high concentrations of $\mathrm{rPrP}^{\mathrm{Sc}}$ in the thalamus, corpus callosum, and parts of the cerebellum, but almost none in the hippocampus (Safar et al., 2005a). Recently, $\mathrm{sPrP}^{\mathrm{Sc}}$ was isolated from prion-infected Syrian hamster brains and shown to be sensitive to trypsin as well as to PK. Interestingly, the $\mathrm{R} 229$ residue in PrP, a part of the R2 epitope, was particularly susceptible to digestion by trypsin (Pastrana et al., 2006). With the support of this evidence, we consider it likely that the trypsinsensitive $\operatorname{PrP}^{\mathrm{Sc}}$ detected by the $\mathrm{R} 2$ antibody in our study is in fact $\mathrm{sPrP}^{\mathrm{Sc}}$.

Although $\mathrm{rPrP}^{\mathrm{Sc}}$ in amyloid form can be easily detected in some types of prion disease, amyloid formation is suspected to be a protective mechanism (Prusiner et al., 1990; Bucciantini et al., 2002; Caughey and Lansbury, 2003). In our view, it is likely that infectious prions in their native environment exist as small aggregates or oligomers, and we suspect that the infectious monomer may be a dimer or trimer (Gabizon et al., 1987, 1988; BellingerKawahara et al., 1988; Govaerts et al., 2004; Wille et al., 2007). Little is known about the subcellular location of the soluble, oligomeric forms of $\mathrm{PrP}^{\mathrm{Sc}}$ that are likely to be most harmful. Our study shows that the R2 antibody recognizes cell-associated, trypsin-sensitive forms of $\mathrm{PrP}^{\mathrm{Sc}}$ and is a valuable tool for localizing $\mathrm{PrP}^{\mathrm{Sc}}$. Our results further reveal that $\mathrm{PrP}^{\mathrm{Sc}}$ is concentrated in early/recycling endosomes of small neurites in prion-infected hippocampus. These vesicles may be sites for $\mathrm{PrP}^{\mathrm{C}}$-to- $\mathrm{PrP}^{\mathrm{Sc}}$ conversion or $\mathrm{PrP}^{\mathrm{Sc}}$ toxicity.

\section{References}

Arnold JE, Tipler C, Laszlo L, Hope J, Landon M, Mayer RJ (1995) The abnormal isoform of the prion protein accumulates in late-endosomelike organelles in scrapie-infected mouse brain. J Pathol 176:403-411.

Bellinger-Kawahara CG, Kempner E, Groth D, Gabizon R, Prusiner SB (1988) Scrapie prion liposomes and rods exhibit target sizes of 55,000 Da. Virology 164:537-541.

Biasini E, Seegulam ME, Patti BN, Solforosi L, Medrano AZ, Christensen HM, Senatore A, Chiesa R, Williamson RA, Harris DA (2008) Non-infectious aggregates of the prion protein react with several $\operatorname{PrP}(\mathrm{Sc})$-directed antibodies. J Neurochem, in press.

Borchelt DR, Taraboulos A, Prusiner SB (1992) Evidence for synthesis of scrapie prion proteins in the endocytic pathway. J Biol Chem 267:16188-16199.

Bouzamondo-Bernstein E, Hopkins SD, Spilman P, Uyehara-Lock J, Deering C, Safar J, Prusiner SB, Ralston HJ 3rd, DeArmond SJ (2004) The neu- 
rodegeneration sequence in prion diseases: evidence from functional, morphological and ultrastructural studies of the GABAergic system. J Neuropathol Exp Neurol 63:882-899.

Brandner S, Isenmann S, Raeber A, Fischer M, Sailer A, Kobayashi Y, Marino S, Weissmann C, Aguzzi A (1996) Normal host prion protein necessary for scrapie-induced neurotoxicity. Nature 379:339-343.

Bucciantini M, Giannoni E, Chiti F, Baroni F, Formigli L, Zurdo J, Taddei N, Ramponi G, Dobson CM, Stefani M (2002) Inherent toxicity of aggregates implies a common mechanism for protein misfolding diseases. Nature 416:507-511.

Büeler H, Aguzzi A, Sailer A, Greiner RA, Autenried P, Aguet M, Weissmann C (1993) Mice devoid of PrP are resistant to scrapie. Cell 73:1339-1347.

Campana V, Sarnataro D, Zurzolo C (2005) The highways and byways of prion protein trafficking. Trends Cell Biol 15:102-111.

Caughey B, Lansbury PT (2003) Protofibrils, pores, fibrils, and neurodegeneration: separating the responsible protein aggregates from the innocent bystanders. Annu Rev Neurosci 26:267-298.

Caughey B, Raymond GJ (1991) The scrapie-associated form of PrP is made from a cell surface precursor that is both protease- and phospholipasesensitive. J Biol Chem 266:18217-18223.

Caughey B, Race RE, Ernst D, Buchmeier MJ, Chesebro B (1989) Prion protein biosynthesis in scrapie-infected and uninfected neuroblastoma cells. J Virol 63:175-181.

Cohen FE, Prusiner SB (1998) Pathologic conformations of prion proteins. Annu Rev Biochem 67:793-819.

Coleman M (2005) Axon degeneration mechanisms: commonality amid diversity. Nat Rev Neurosci 6:889-898.

DeArmond SJ (2004) Discovering the mechanisms of neurodegeneration in prion diseases. Neurochem Res 29:1979-1998.

DeArmond SJ, Sánchez H, Yehiely F, Qiu Y, Ninchak-Casey A, Daggett V, Camerino AP, Cayetano J, Rogers M, Groth D, Torchia M, Tremblay P, Scott MR, Cohen FE, Prusiner SB (1997) Selective neuronal targeting in prion disease. Neuron 19:1337-1348.

Demuro A, Mina E, Kayed R, Milton SC, Parker I, Glabe CG (2005) Calcium dysregulation and membrane disruption as a ubiquitous neurotoxic mechanism of soluble amyloid oligomers. J Biol Chem 280:17294-17300.

Ferrer I, Puig B, Blanco R, Martí E (2000) Prion protein deposition and abnormal synaptic protein expression in the cerebellum in CreutzfeldtJakob disease. Neuroscience 97:715-726.

Fournier JG, Escaig-Haye F, Grigoriev V (2000) Ultrastructural localization of prion proteins: physiological and pathological implications. Microsc Res Tech 50:76-88.

Gabizon R, McKinley MP, Prusiner SB (1987) Purified prion proteins and scrapie infectivity copartition into liposomes. Proc Natl Acad Sci U S A 84:4017-4021.

Gabizon R, McKinley MP, Groth DF, Kenaga L, Prusiner SB (1988) Properties of scrapie prion protein liposomes. J Biol Chem 263:4950-4955.

Govaerts C, Wille H, Prusiner SB, Cohen FE (2004) Evidence for assembly of prions with left-handed beta-helices into trimers. Proc Natl Acad Sci U S A 101:8342-8347.

Grigoriev V, Escaig-Haye F, Streichenberger N, Kopp N, Langeveld J, Brown P, Fournier JG (1999) Submicroscopic immunodetection of PrP in the brain of a patient with a new-variant of Creutzfeldt-Jakob disease. Neurosci Lett 264:57-60.

Ishikura N, Clever JL, Bouzamondo-Bernstein E, Samayoa E, Prusiner SB, Huang EJ, DeArmond SJ (2005) Notch-1 activation and dendritic atrophy in prion disease. Proc Natl Acad Sci U S A 102:886-891.

Jeffrey M, Goodsir CM, Bruce ME, McBride PA, Scott JR (1994) Infectionspecific prion protein $(\mathrm{PrP})$ accumulates on neuronal plasmalemma in scrapie-infected mice. Ann N Y Acad Sci 724:327-330.

Jeffrey M, Halliday WG, Bell J, Johnston AR, MacLeod NK, Ingham C, Sayers AR, Brown DA, Fraser JR (2000) Synapse loss associated with abnormal $\mathrm{PrP}$ precedes neuronal degeneration in the scrapie-infected murine hippocampus. Neuropathol Appl Neurobiol 26:41-54.

Jeffrey M, Goodsir CM, Race RE, Chesebro B (2004) Scrapie-specific neuronal lesions are independent of neuronal PrP expression. Ann Neurol 55:781-792.

Kanaani J, Prusiner SB, Diacovo J, Baekkeskov S, Legname G (2005) Recombinant prion protein induces rapid polarization and development of synapses in embryonic rat hippocampal neurons in vitro. J Neurochem 95:1373-1386.

Kovács GG, Preusser M, Strohschneider M, Budka H (2005) Subcellular localization of disease-associated prion protein in the human brain. Am J Pathol 166:287-294.

Liberski PP, Budka H (1999) Neuroaxonal pathology in Creutzfeldt-Jakob disease. Acta Neuropathol (Berl) 97:329-334.

Mayhew TM (2005) How to count your gold: a tutorial on TEM immunogold label quantification. Microscopy and Analysis 19:9-12.

Mayhew TM, Desoye G (2004) A simple method for comparing immunogold distributions in two or more experimental groups illustrated using GLUT1 labelling of isolated trophoblast cells. Placenta 25:580-584.

Mayhew TM, Lucocq JM, Griffiths G (2002) Relative labelling index: a novel stereological approach to test for non-random immunogold labelling of organelles and membranes on transmission electron microscopy thin sections. J Microsc 205:153-164.

McKinley MP, Taraboulos A, Kenaga L, Serban D, Stieber A, DeArmond SJ, Prusiner SB, Gonatas N (1991) Ultrastructural localization of scrapie prion proteins in cytoplasmic vesicles of infected cultured cells. Lab Invest 65:622-630.

Mironov A Jr, Latawiec D, Wille H, Bouzamondo-Bernstein E, Legname G, Williamson RA, Burton D, DeArmond SJ, Prusiner SB, Peters PJ (2003) Cytosolic prion protein in neurons. J Neurosci 23:7183-7193.

Mouillet-Richard S, Ermonval M, Chebassier C, Laplanche JL, Lehmann S, Launay JM, Kellermann O (2000) Signal transduction through prion protein. Science 289:1925-1928.

Mouillet-Richard S, Pietri M, Schneider B, Vidal C, Mutel V, Launay JM, Kellermann O (2005) Modulation of serotonergic receptor signaling and cross-talk by prion protein. J Biol Chem 280:4592-4601.

Mundigl O, Matteoli M, Daniell L, Thomas-Reetz A, Metcalf A, Jahn R, De Camilli P (1993) Synaptic vesicle proteins and early endosomes in cultured hippocampal neurons: differential effects of Brefeldin $\mathrm{A}$ in axon and dendrites. J Cell Biol 122:1207-1221.

Muramoto T, Kitamoto T, Tateishi J, Goto I (1992) The sequential development of abnormal prion protein accumulation in mice with Creutzfeldt-Jakob disease. Am J Pathol 140:1411-1420.

Nailon WH, Ironside JW (2000) Variant Creutzfeldt-Jakob disease: immunocytochemical studies and image analysis. Microsc Res Tech 50:2-9.

Oesch B, Westaway D, Wälchli M, McKinley MP, Kent SB, Aebersold R, Barry RA, Tempst P, Teplow DB, Hood LE (1985) A cellular gene encodes scrapie PrP 27-30 protein. Cell 40:735-746.

Parton RG, Simons K, Dotti CG (1992) Axonal and dendritic endocytic pathways in cultured neurons. J Cell Biol 119:123-137.

Pastrana MA, Sajnani G, Onisko B, Castilla J, Morales R, Soto C, Requena JR (2006) Isolation and Characterization of a Proteinase K-Sensitive $\operatorname{PrP}(\mathrm{Sc})$ Fraction. Biochemistry 45:15710-15717.

Peretz D, Williamson RA, Matsunaga Y, Serban H, Pinilla C, Bastidas RB, Rozenshteyn R, James TL, Houghten RA, Cohen FE, Prusiner SB, Burton DR (1997) A conformational transition at the $\mathrm{N}$ terminus of the prion protein features in formation of the scrapie isoform. J Mol Biol 273:614-622.

Peters A, Palay SL, Webster HD (1991) The fine structure of the nervous system. Neurons and their supporting cells, Ed 3. New York: Oxford UP.

Peters PJ, Mironov A Jr, Peretz D, van Donselaar E, Leclerc E, Erpel S, DeArmond SJ, Burton DR, Williamson RA, Vey M, Prusiner SB (2003) Trafficking of prion proteins through a caveolae-mediated endosomal pathway. J Cell Biol 162:703-717.

Peters PJ, Bos E, Griekspoor A (2006) Cryo-immunogold electron microscopy. In: Current protocols in cell biology (Bonifacino J, Dasso M, Harford J, Lippincott-Schwartz J, Yamada K, eds), pp 4.7.1-4.7.19. New York: Wiley.

Prekeris R, Klumperman J, Chen YA, Scheller RH (1998) Syntaxin 13 mediates cycling of plasma membrane proteins via tubulovesicular recycling endosomes. J Cell Biol 143:957-971.

Prekeris R, Foletti DL, Scheller RH (1999) Dynamics of tubulovesicular recycling endosomes in hippocampal neurons. J Neurosci 19:10324-10337.

Privat N, Sazdovitch V, Seilhean D, LaPlanche JL, Hauw JJ (2000) PrP immunohistochemistry: different protocols, including a procedure for long formalin fixation, and a proposed schematic classification for deposits in sporadic Creutzfeldt-Jakob disease. Microsc Res Tech 50:26-31.

Prusiner SB, Scott M, Foster D, Pan KM, Groth D, Mirenda C, Torchia M, Yang SL, Serban D, Carlson GA, et al (1990) Transgenetic studies implicate interactions between homologous PrP isoforms in scrapie prion replication. Cell 63:673-686.

Rezaei H, Eghiaian F, Perez J, Doublet B, Choiset Y, Haertle T, Grosclaude J 
(2005) Sequential generation of two structurally distinct ovine prion protein soluble oligomers displaying different biochemical reactivities. J Mol Biol 347:665-679.

Ryder SJ, Spencer YI, Bellerby PJ, March SA (2001) Immunohistochemical detection of PrP in the medulla oblongata of sheep: the spectrum of staining in normal and scrapie-affected sheep. Veterinary Record 148:7-13.

Safar J, Wille H, Itri V, Groth D, Serban H, Torchia M, Cohen FE, Prusiner SB (1998) Eight prion strains have $\operatorname{PrP}(\mathrm{Sc})$ molecules with different conformations. Nat Med 4:1157-1165.

Safar JG, DeArmond SJ, Kociuba K, Deering C, Didorenko S, BouzamondoBernstein E, Prusiner SB, Tremblay P (2005a) Prion clearance in bigenic mice. J Gen Virol 86:2913-2923.

Safar JG, Geschwind MD, Deering C, Didorenko S, Sattavat M, Sanchez H, Serban A, Vey M, Baron H, Giles K, Miller BL, Dearmond SJ, Prusiner SB (2005b) Diagnosis of human prion disease. Proc Natl Acad Sci U S A 102:3501-3506.

Sandberg MK, Wallén P, Wikström MA, Kristensson K (2004) Scrapieinfected GT1-1 cells show impaired function of voltage-gated N-type calcium channels $(\mathrm{Ca}(\mathrm{v}) 2.2)$ which is ameliorated by quinacrine treatment. Neurobiol Dis 15:143-151.

Santuccione A, Sytnyk V, Leshchyns'ka I, Schachner M (2005) Prion pro- tein recruits its neuronal receptor NCAM to lipid rafts to activate p59fyn and to enhance neurite outgrowth. J Cell Biol 169:341-354.

Schmitt-Ulms G, Legname G, Baldwin MA, Ball HL, Bradon N, Bosque PJ, Crossin KL, Edelman GM, DeArmond SJ, Cohen FE, Prusiner SB (2001) Binding of neural cell adhesion molecules (N-CAMs) to the cellular prion protein. J Mol Biol 314:1209-1225.

Sun A, Nguyen XV, Bing G (2002) Comparative analysis of an improved thioflavin-s stain, Gallyas silver stain, and immunohistochemistry for neurofibrillary tangle demonstration on the same sections. J Histochem Cytochem 50:463-472.

Thackray AM, Hopkins L, Bujdoso R (2007) Proteinase K-sensitive diseaseassociated ovine prion protein revealed by conformation-dependent immunoassay. Biochem J 401:475-483.

Tzaban S, Friedlander G, Schonberger O, Horonchik L, Yedidia Y, Shaked G, Gabizon R, Taraboulos A (2002) Protease-sensitive scrapie prion protein in aggregates of heterogeneous sizes. Biochemistry 41:12868-12875.

Wille H, Govaerts C, Borovinskiy A, Latawiec D, Downing KH, Cohen FE, Prusiner SB (2007) Electron crystallography of the scrapie prion protein complexed with heavy metals. Archives of Biochemistry and Biophysics 467:239-248.

Williamson RA, Peretz D, Pinilla C, Ball H, Bastidas RB, Rozenshteyn R, Houghten RA, Prusiner SB, Burton DR (1998) Mapping the prion protein using recombinant antibodies. J Virol 72:9413-9418. 